\title{
STUDY OF GROWTH KINETICS OF INTERMETALLIC PHASES IN CU-Sn SOLDER JOINTS UNDER THE CONDITIONS OF REACTIVE DIFFUSION
}

\author{
1'Jaromír DRÁPALA, ${ }^{1}$ Gabriela KOSTIUKOVÁ, ${ }^{1}$ Hana FRANCOVÁ, ${ }^{1}$ Monika LOSERTOVÁ, \\ ${ }^{2}$ Petr KUBÍČEK \\ ${ }^{1}$ VSB - Technical University of Ostrava, Ostrava, Czech Republic, EU, Jaromir.Drapala@vsb.cz \\ ${ }^{2} \mathrm{Na}$ Čtvrti 14, 70300 Ostrava - Hrabůvka, Czech Republic, EU
}

https://doi.org/10.37904/metal.2021.4250

\begin{abstract}
The content of the paper is a brief description of the basic characteristics of the reactive diffusion in the dissolution of solid copper in the melt of tin solder. Furthermore, it deals with the theory of growth kinetics of intermetallic phases during heat treatment, and a description of lead-free solders and related problems during soldering. Experimental part contains layout and design of experiments suitable for the study of reactive diffusion, metallographic study and x-ray EDX microanalysis of samples, the calculations of diffusion flows and determination of the rate constants of dissolution.
\end{abstract}

Keywords: Reactive diffusion, dissolving, lead-free solders, tin-copper system, intermetallic phase

\section{INTRODUCTION}

The reactive diffusion occurs at connecting two solid phases of different chemical compositions as well as at the contact of the solid phase $A$ with the melt $B[1-10]$. The solid phase metal $A$ dissolves in metal $B$ and atoms of metal $A$ diffuse into the melt $B$, usually at the presence of natural convections. Atoms $B$ from the melt diffuse into metal $A$, which dissolves simultaneously and a number of intermetallic phases $A_{m} B_{n}$ may form at the metal A surface. These phases grow in metal $A$ with the growing dissolving time. At experiments the temperature $T$ is opted so that it is higher than the melting temperature of metal $B$ and lower than the melting temperature of metal $A$. The rate of dissolving and the growth of phases depend significantly on the temperature and time. At higher temperatures these processes are very fast compared with the processes in the solid phase. The melt $B$ is gradually enriched with the dissolving metal $A$ until saturation is achieved and the process of dissolving terminates stops. Concentrations corresponding to the relevant phase diagram - i.e. equilibrium concentrations, stabilize on interface boundaries in the solid phase.

Analogical behavior and formation of new phases can also be expected in more complicated binary or ternary systems, in which more intermetallic compounds exist (Figure 1). The reactive diffusion will result in coexistence of several consecutive phases of solid solutions. A characteristic feature of multiphase diffusion is a gradual course of the curve demonstrating the dependence of the concentration $c(x, t)$ on the coordinate $x$. This gradual character of the curve is caused by the fact that primary solid solutions and intermetallic phases create at the reaction between two mutually diffusing substances (components). Two-phase areas separating solid solutions and intermetallic phases in equilibrium diagrams do not create. This shows discordance between the course of diffusion and the equilibrium diagram. The height of individual grades is given by width of two-phase areas in the equilibrium diagram. The width of the creating phase depends on the concentration curve of each phase and its rate of growth [11]. Some our results at the study of the reactive diffusion were published in the journal Defect and Diffusion Forum [12-15] and [16].

Unlike the diffusion in single-phase systems, reactions taking place on the interface between individual phases assert at diffusion in multiphase systems. It is important whether these reactions are efficiently fast and do not 
retard the course of diffusion. At the beginning of the diffusion process, when the concentration differences are significant, this retardation has to be taken into account. As soon as layers of individual intermetallic phases (even if very thin) create, the retardation effect of reaction rates on the phase interface generally disappears.

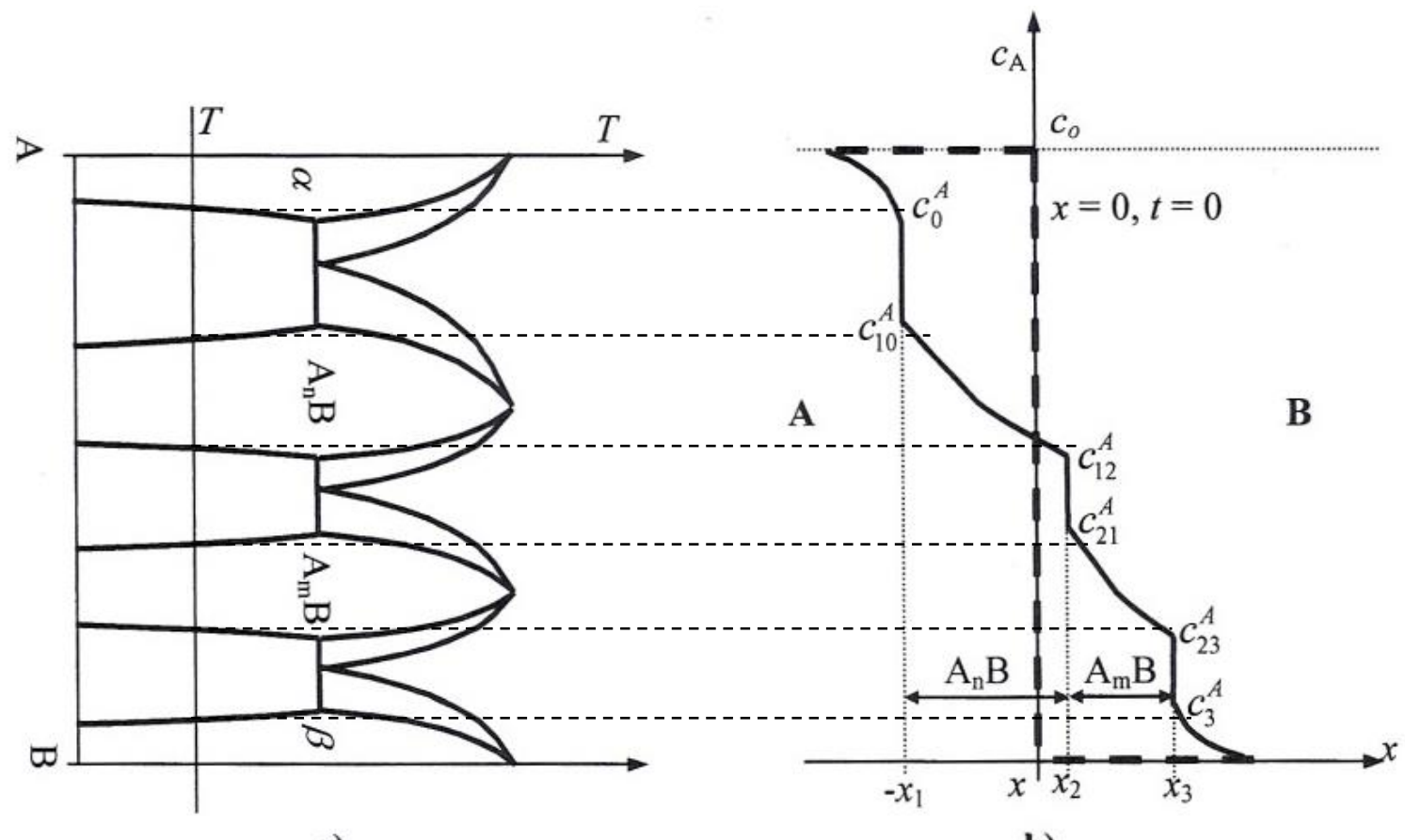

a)

b)

Figure 1 Multiphase diffusion in the A-B binary system a) hypothetic binary system, b) gradual course of concentration

A growth of phases in metal $A$ after long-term heating and detecting the thickness of layers in the diffusion couples metal A - melt B in systems copper - lead free solder will be presented in this paper.

\section{THEORY OF THE PLANAR DISSOLUTION}

For the planar interface boundary when the interface shift during the dissolution is perpendicular to the interface, the relation is obtained [12-17]

$$
\chi(t)=\frac{\rho_{2}}{\rho_{1}} \frac{1-e^{-K_{o} t}}{\frac{1-c_{o}}{c_{o}}+e^{-K_{o} t}} I_{o},
$$

where: $I_{0}$ is the width of the melt column at time $t=0, \rho_{2}, \rho_{1}$ are densities of the solid and liquid phases, $\chi(t)$ is the shift of the interface boundary during dissolution and $c_{o}$ is the saturated concentration of the metal $A$ in the melt $\mathrm{B}$ at the temperature $T$. The following holds for the time dependence $c(t)$ of the metal $\mathrm{A}$ in the melt $\mathrm{B}$

$c(t)=\frac{\chi(t)}{a+\chi(t)}, \quad a=\frac{\rho_{2} I_{0}}{\rho_{1}}$.

Relation (1) describes the time dependence of planar dissolution. $K_{o}$ is the rate constant of dissolution. Neither the diffusion of atoms $B$ from the melt into solid phase $A$ nor the volume changes during dissolution were taken into account in the model. Convection in the melt will influence the rate of dissolution and therefore the exact value $K_{o}$ will partly depend on the geometry, in which the planar dissolution takes place. The relation (1) may be used for an approximate evaluation of the rate constant of dissolving $K_{0}$ under precisely defined experimental conditions. Figure 2 illustrates the calculated dependences $\chi(t)$ for $\mathrm{Cu}-\mathrm{Sn}$ system. The values 
of density ratios $\rho_{2} / \rho_{1} \approx 0.766$ for $T=400{ }^{\circ} \mathrm{C}, c_{0}=0.115$ (from the phase diagram $\mathrm{Cu}-\mathrm{Sn}$ ), $l_{0}=1 \mathrm{~cm}$ at $K_{0}=$ $(0.3 \div 1.2) \cdot 10^{-5} \mathrm{~s}^{-1}$ were used in the calculations. Time dependences of the component $\mathrm{A}$ concentration in the melt, assuming perfect melt homogenisation, are obtained from relations (1) and (2)

$c_{\mathrm{A}}(t)=c_{o}\left(1-e^{-K_{o} t}\right)$

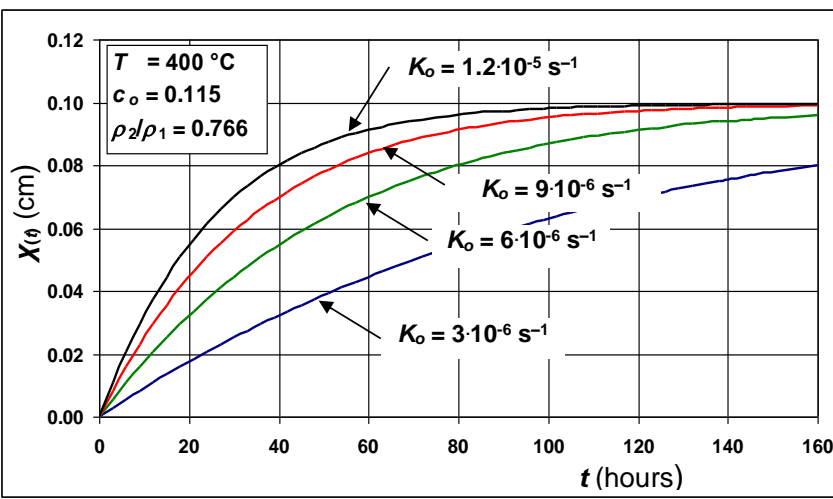

(a)

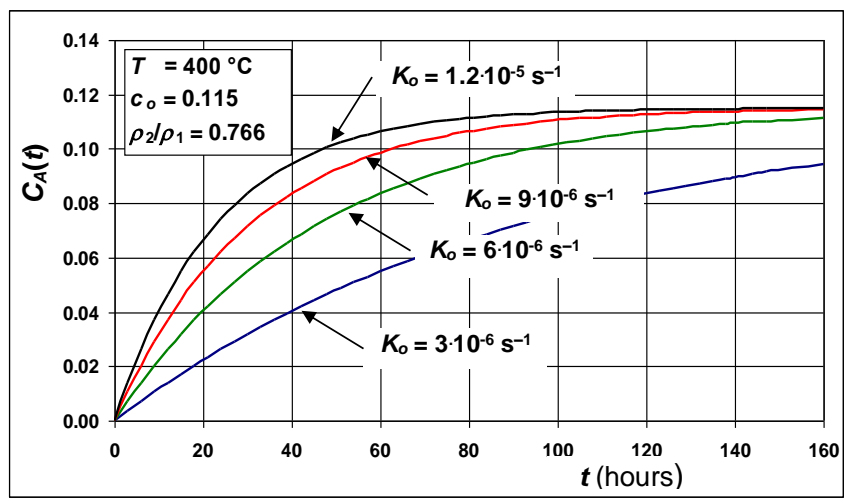

(b)

Figure 2 Graphs of functions (a) $\chi(t)$ - eq. (1) and (b) $c_{A}(t)$ - eq. (3) for the liquid temperature $400{ }^{\circ} \mathrm{C}$ in $\mathrm{Cu}-$ Sn system and various values of $K_{o}=(0.3 \div 1.2) \cdot 10^{-5} \mathrm{~s}^{-1}$ for planar dissolution

\section{EXPERIMENT}

\subsection{Experimental study of growth of phases and reactive diffusion on planar specimens}

The uni-directional experiment was realized using the "sandwich" specimens. A layer of a tin-based solder was inserted between two Cu plates. Three compositions of lead-free solder alloys were used: pure Sn, Sn97Cu3, Sn95.5Ag3.8Cu0.7 (in wt\%). Two plates of high-purity copper were $0.5 \mathrm{~mm}$ thick, the other dimensions were $20 \times 10 \mathrm{~mm}$. The Sn-based solders inserted between the two Cu plates were rolled down to the thickness 0.6 $\mathrm{mm}$. Copper plates were covered by a layer of suitable flux. The soldered joint was created using a heating element. The sandwiches were held at the temperature $255 \div 285{ }^{\circ} \mathrm{C}$ (above liquid) for $40-120$ seconds. Prepared specimens were subsequently annealed at $T=300^{\circ} \mathrm{C}$ for $18,24,48$ and $92 \mathrm{~h}$.

The $n-\mathrm{Cu}_{6} \mathrm{Sn}_{5}$ grows into during annealing at the temperature $T=300{ }^{\circ} \mathrm{C}$ on the interface with the $\mathrm{Cu}$. Copper dissolves in liquid Sn-based solder up to the saturation concentration about 4 at.\% (2.2 wt.\%) Cu. As a consequence of $\mathrm{Sn}$ diffusion into solid $\mathrm{Cu}$, phase $\eta$ grows with time and subsequently phase $\varepsilon\left(\mathrm{Cu}_{3} \mathrm{Sn}, 75\right.$ at.\% $\mathrm{Cu}$ and 25 at.\% $\mathrm{Sn}$ ) appears close to the pure $\mathrm{Cu}$. The specimens were cooled on the air after annealing and the temperature decreased relatively quickly below the eutectic temperature $227{ }^{\circ} \mathrm{C}$. The joint

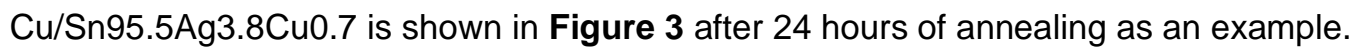

At X-ray microanalyses we only obtain this value on the straight line, which should be perpendicular to the interface boundary. X-ray microanalysis of concentration profiles for $\mathrm{Cu} / \mathrm{Sn}$ joint is in Figure 4.

The growth of phase $\varepsilon$ should proceed with time according to parabolic law $\chi_{\varepsilon}(t)=\alpha \sqrt{t}$ where $\chi_{\varepsilon}(t)$ is the thickness of $\varepsilon$ and $\alpha$ phases, it is the constant which characterizes the rate of phase growth. The values $\chi_{\varepsilon}(t)$ can be obtained experimentally using the metallographic pictures from relatively large areas. The evaluated values $\alpha$ from the metallography and X-ray EDX microanalysis are presented in Table 1 . The calculated values $\alpha$ for $\mathrm{Cu} / \mathrm{Sn}, \mathrm{Cu} / \mathrm{Sn} 97 \mathrm{Cu} 3$ and $\mathrm{Cu} / \mathrm{SnAg3.8Cu0.7}$ joints from EDX measurements were in very good agreement. They were determined for $t=18$ to 92 hours. 


\section{ME'TAL
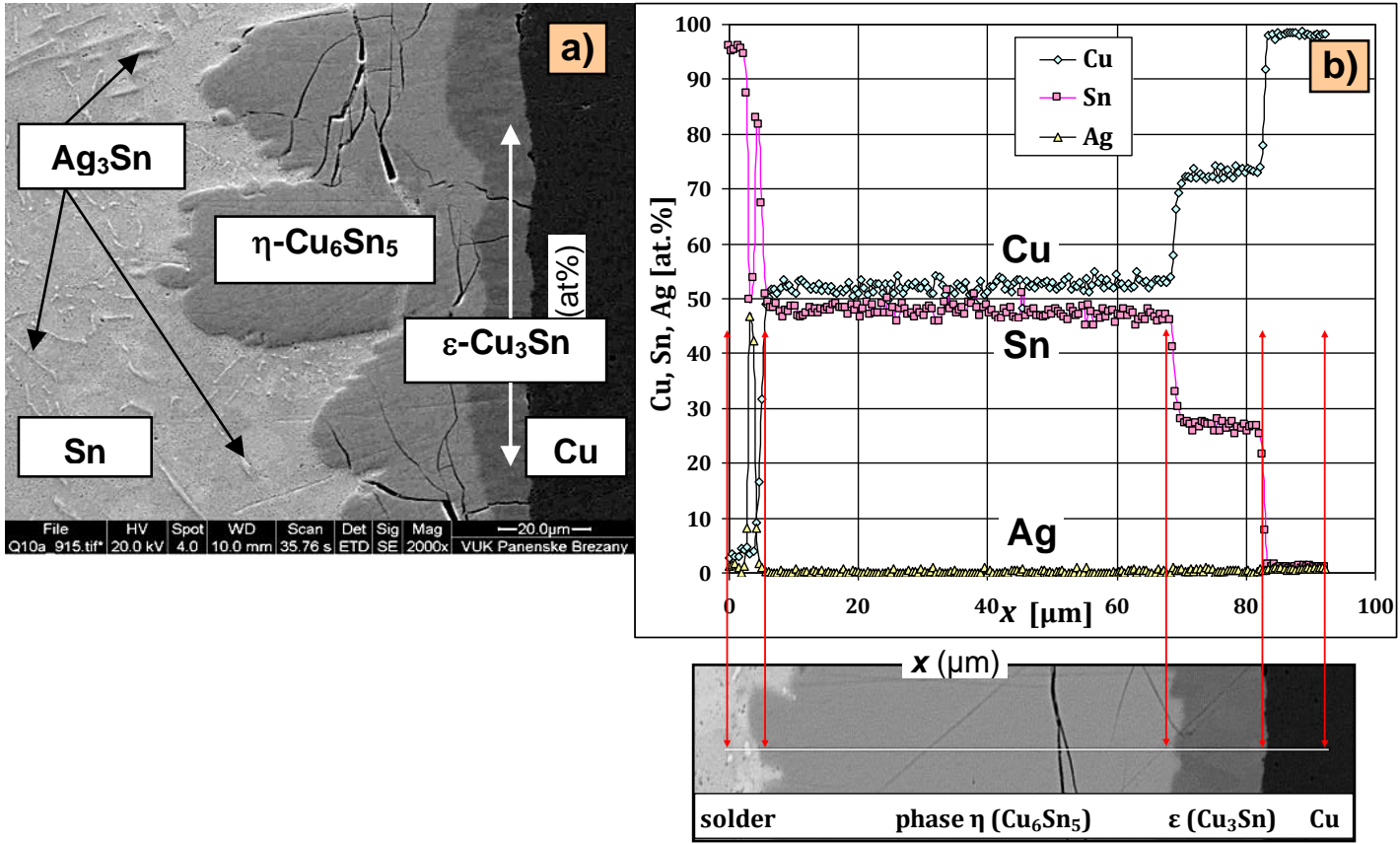

Figure 3 Microstructure a) and concentration profiles b) in the joint $\mathrm{Cu} / \mathrm{SnAg} 3.8 \mathrm{Cu} 0.7$ annealed at $300^{\circ} \mathrm{C}$ for 24 hours

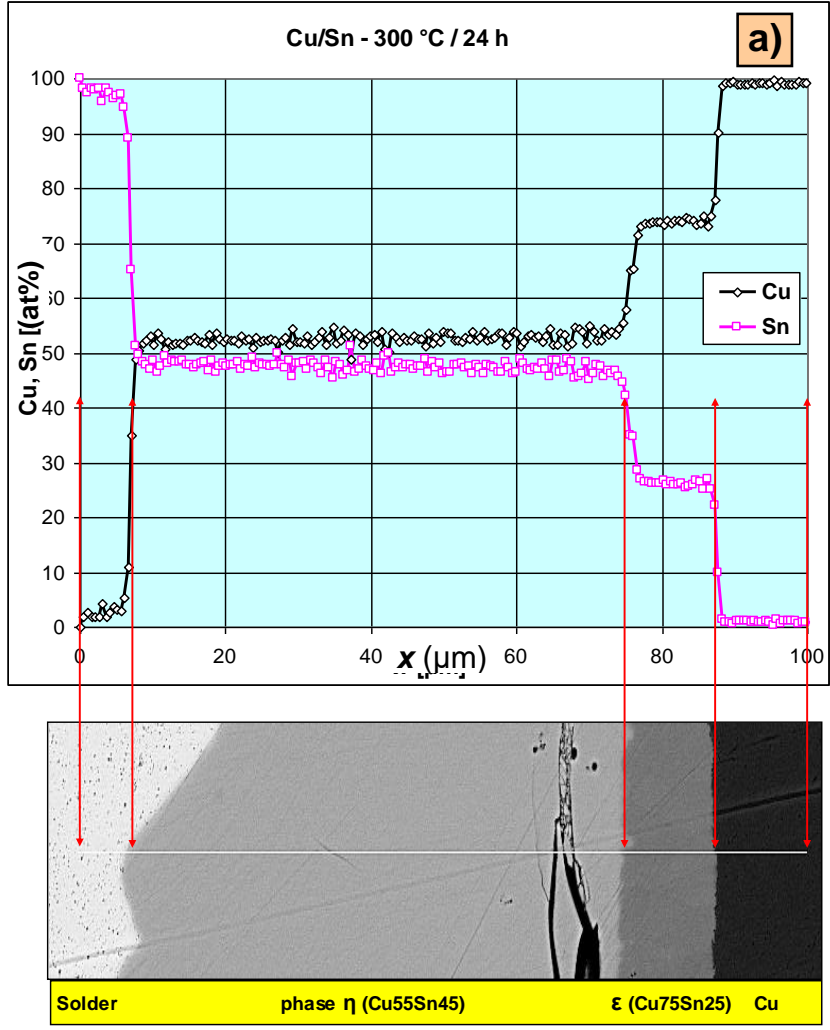

a) $T=300^{\circ} \mathrm{C}, t=24 \mathrm{~h}$

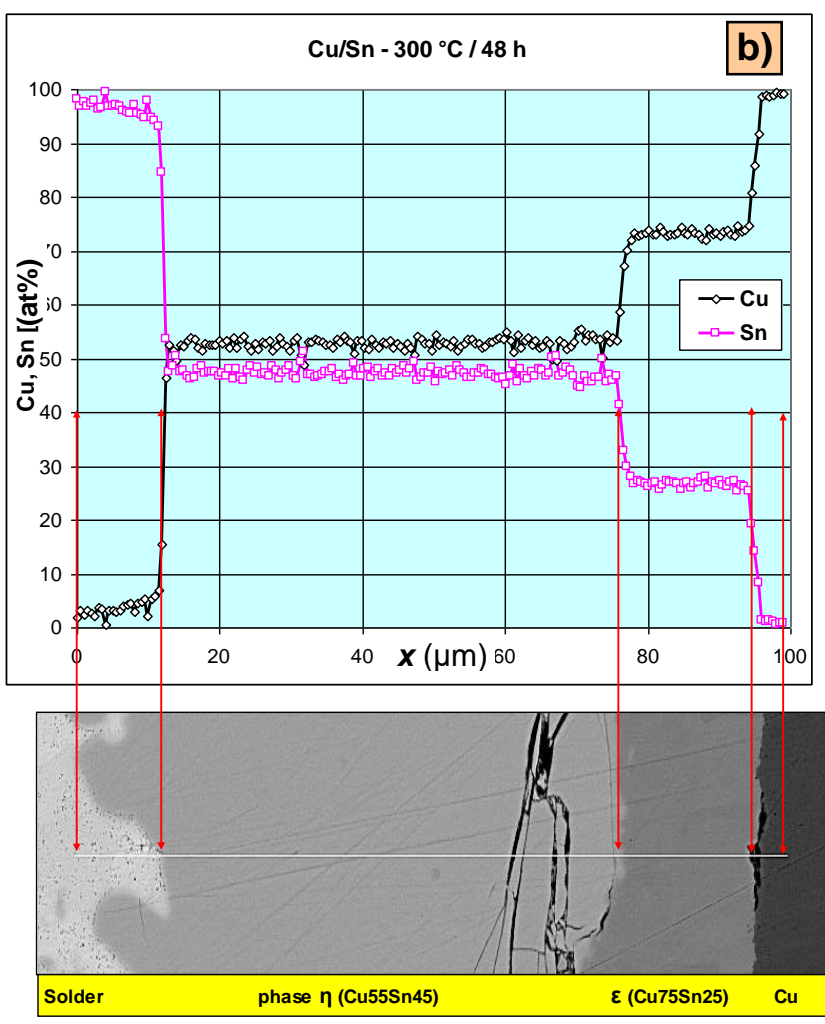

b) $T=300{ }^{\circ} \mathrm{C}, t=48 \mathrm{~h}$

Figure 4 Microstructure and concentration profiles in the $\mathrm{Cu} / \mathrm{Sn}$ joint 
Table 1 Evaluation of the rate of growth of phase $\varepsilon$ in „sandwich“ specimens at temperature $T=300{ }^{\circ} \mathrm{C}$

\begin{tabular}{|c|c|c|c|c|c|c|c|}
\hline EDX analysis & $\begin{array}{c}T \\
\text { (h) }\end{array}$ & $\begin{array}{l}\alpha \cdot 10^{6} \\
\left(\mathrm{~cm} / \mathrm{s}^{1 / 2}\right)\end{array}$ & $\begin{array}{c}\text { mean } \alpha \\
10^{6}\left(\mathrm{~cm} / \mathrm{s}^{1 / 2}\right)\end{array}$ & Metallography & $\begin{array}{c}T \\
\text { (h) }\end{array}$ & $\begin{array}{l}\alpha \cdot 10^{6} \\
\left(\mathrm{~cm} / \mathrm{s}^{1 / 2}\right)\end{array}$ & $\begin{array}{c}\operatorname{mean} \alpha \cdot \\
10^{6}\left(\mathrm{~cm} / \mathrm{s}^{1 / 2}\right)\end{array}$ \\
\hline \multirow{4}{*}{$\mathrm{Cu} / \mathrm{Sn}$} & & & \multirow{4}{*}{3.33} & \multirow{4}{*}{$\mathrm{Cu} / \mathrm{Sn}$} & 18 & 5.84 & \multirow{4}{*}{5.57} \\
\hline & 24 & 3.23 & & & 24 & 5.10 & \\
\hline & 48 & 3.43 & & & 48 & 4.38 & \\
\hline & & & & & 92 & 6.95 & \\
\hline \multirow{4}{*}{$\mathrm{Cu} / \mathrm{Sn} 97 \mathrm{Cu} 3$} & & & \multirow{4}{*}{3.25} & \multirow{4}{*}{$\mathrm{Cu} / \mathrm{Sn} 97 \mathrm{Cu} 3$} & 18 & 6.50 & \multirow{4}{*}{5.41} \\
\hline & 24 & 3.16 & & & 24 & 6.23 & \\
\hline & 48 & 3.34 & & & 48 & 4.0 & \\
\hline & & & & & 92 & 4.92 & \\
\hline \multirow{4}{*}{$\begin{array}{l}\mathrm{Cu} / \mathrm{Sn} 95.5 \\
\mathrm{Ag} 3.8 \mathrm{Cu} 0.7\end{array}$} & 18 & 6.12 & \multirow{4}{*}{4.76} & \multirow{4}{*}{$\begin{array}{l}\mathrm{Cu} / \mathrm{Sn} 95.5 \\
\mathrm{Ag3.8Cu0.7}\end{array}$} & 18 & 6.6 & \multirow{4}{*}{4.27} \\
\hline & 24 & 3.42 & & & 24 & 3.63 & \\
\hline & 48 & 4.30 & & & 48 & 2.40 & \\
\hline & 92 & 5.21 & & & 92 & 4.46 & \\
\hline
\end{tabular}

\subsection{Calculation of $\mathrm{Sn}$ diffusivities at $T=300^{\circ} \mathrm{C}$ based on the growth of the phase $\varepsilon$ into $\mathrm{Cu}$}

This tentative calculation was performed using Wagner relation [18-20]. Based on the X-ray analysis of concentration curves we searched for the size of interval $\Delta x$, where the Sn concentration in Cu decreased nearly to zero.We can estimate the diffusivity $D$ from the value $\Delta x$ and the known time of annealing $t$ using the equation:

$\frac{\Delta x}{2 \sqrt{D t}} \approx 1.5 ; \quad \operatorname{erfc}(1.5)=0.034$

$\begin{array}{ll}\text { Diffusion joint: } \mathrm{Cu} / \mathrm{Sn}, & t=48 \mathrm{~h}, T=300^{\circ} \mathrm{C}, \Delta x=2 \mu \mathrm{m}, D \approx 2.6 \times 10^{-14} \mathrm{~cm}^{2} / \mathrm{s} . \\ \text { Diffusion joint: } \mathrm{Cu} / \mathrm{Sn} 97 \mathrm{Cu} 3, & t=24 \mathrm{~h}, T=300^{\circ} \mathrm{C}, \Delta x \approx 2 \mu \mathrm{m}, D \approx 5.1 \times 10^{-14} \mathrm{~cm}^{2} / \mathrm{s} .\end{array}$

\section{DISCUSSION}

Binary system $A-B$, when element $A$ is in the solid phase, was opted as a model example. During the dissolution of the melt $B$ is being saturated with metal $A$, the melt viscosity may change and then natural convection in the melt decelerates with time. This also partly decelerates the rate of dissolution. We have to realize that the values of rate constant of dissolution $K_{o}$ determined experimentally only correspond exactly to a particular geometry and conditions of experiment considering the character of convections in the melt corresponding to particular experimental arrangement.

At dissolution an increased concentration of substance $A$ in melt $B$ is near the interface boundary and at the experiments in question the melt homogenization proceeds due to natural convection in the melt, e.g. even due to small temperature gradient, different densities in the solid phase and melt, vibrations and shakes, etc. With extending the time of dissolution during experiments, the rate of convection decreases due to increasing the substance A concentration in the melt, because the viscosity of melt usually increases. When the saturated concentration in the melt is achieved, dissolution is terminated, equilibrium is set and the interface boundary movement may only proceed in consequence of diffusion in the solid phase. However, this process is mostly by several orders slower than the interface boundary movement at the metal dissolution in the melt and that is why it was neglected in deriving of the interface boundary movement at dissolution. It has to be marked that the values of the rate constant of dissolution $K_{o}$ determined experimentally only correspond to a particular 
geometry and conditions of experiment due to the character of the convection in the melt pertaining to a particular experimental arrangement.

When observing the growth of phases in system $\mathrm{Cu}-\mathrm{Sn}$ on planar specimens at the temperature $T=300{ }^{\circ} \mathrm{C}$ a very irregular growth of phase $\eta$, especially into the melt, was discovered and estimates of the rate of growth of phase $\varepsilon$ into $\mathrm{Cu}$ according to the parabolic law were performed as well for the other lead-free solders.

A fast growth of phases in metal $A$ after long-term heating and detecting the thickness of layers with these phases, i.e. $\chi_{\varepsilon}(t), \chi_{\eta}(t)$ etc. pose considerable time demands on structural and chemical microanalyses of specimens.

\section{CONCLUSION}

In this paper the problems of reactive diffusion at the contact of solid phase with solder melt were outlined briefly. Examples of particular experimental arrangements were presented. The main intention was to calculate time courses of the solid phase dissolution for the cases of planar geometry. The calculations were started from the equation (1) describing the kinetics of dissolution. As an example we presented concentration profiles in the joints $\mathrm{Cu} / \mathrm{SnAg} 3.8 \mathrm{Cu} 0.7$ annealed at $300^{\circ} \mathrm{C}$ for 24 hours and $\mathrm{Cu} / \mathrm{Sn}$ at $300^{\circ} \mathrm{C}$ for 24 and 48 hours.

\section{ACKNOWLEDGEMENTS}

\section{This work was solved at the Faculty of Materials Science and Technology of VSB - Technical University of Ostrava}

\section{REFERENCES}

[1] LEPINSKICH, B.M. et al. Diffusion of elements in molten metals of iron group. Moscow: Izd. Nauka, 1974.

[2] HEUMANN, T. Mehrphasen Diffusion. in: Diffusion in metallischen Werkstoffen. Leipzig: VEB Deutscher Verlag für Grundstoffindustrie. 1970, pp. 129-142.

[3] KAJIHARA, M. Kinetic features of reactive diffusion in binary systems. In: Bokstein, B.S., Straumal, B.B. Diffusion in Solids - Past, Present and Future. Switzerland: Trans Tech Publications Ltd., 2006, p. 91-95.

[4] GAS, P., BERGMAN, C., CLUGNET, G., BARNA, P., KOVACS, A., LABAR, J. Reactive diffusion in Al/Pt films and the determination of the diffusion coefficients of $\mathrm{Al}$ in amorphous $\mathrm{Al}_{2} \mathrm{Pt}$. In: Diffusion in Materials. DIMAT 2000. Switzerland: Ed. Y. Limoge, J.L. Bocquet, Scitec Publications, 2001, p. 807-814.

[5] FEDOROV,V.V., DJOMINA, E.V., ZASADNY, T.M., KOROLUK, R.I., PRUSAKOVA, M.D., VINOGRADOVA, N.A. Effect of hydrogen on processes of reactive diffusion in a 'metal - protective coating' system. In: Diffusion in Materials. DIMAT 2000. Switzerland: Ed. Y. Limoge, J.L. Bocquet, Scitec Publications, 2001, pp. 1105-1100.

[6] KODENTSOV, A.A., VAN DAL, M.J.H., CSERHÁTI, C., GUSAK, A.M., VAN LOO, F.J.J. Pattering in reactive diffusion. In: Diffusion in Materials. DIMAT 2000. Switzerland: Ed. Y. Limoge, J.L. Bocquet, Scitec Publications, 2001, pp. 1491-1501.

[7] DYBKOV, V.I. Reaction diffusion in binary solid-solid, solid-liquid and solid-gas systems: Common and distinctive features. In: Diffusion in Materials. DIMAT 2000. Switzerland: Ed. Y. Limoge, J.L. Bocquet, Scitec Publications, 2001, pp. 1503-1519.

[8] BERGMAN, C., EMERIC, C., CLUGNET, G., GAS, P. Kinetics of reactive diffusion in Al/Co multilayers. In: Diffusion in Materials. DIMAT 2000. Switzerland: Ed. Y. Limoge, J.L. Bocquet, Scitec Publications, 2001, pp. 1533-1538.

[9] PARITSKAYA, L.N., BOGDANOV, V.V., KAGANOVSKII, Yu.S., LOJKOWSKI, W., KOLESNIKOV, D., PRESZ, A. The kinetics of $\mathrm{Cd}_{16} \mathrm{Cu}_{6}$ intermetallic growth under elevated hydrostatic pressure. In: Diffusion in Materials. DIMAT 2000. Switzerland: Ed. Y. Limoge, J.L. Bocquet, Scitec Publications, 2001, pp. 1539-1544. 
[10] D'HEURLE, F.M., GAS, P., PHILIBERT, J., ZHANG, S.-L. On reactive diffusion: 1) Kinetics, growth and diffusion, 2) Equilibrium? In: Diffusion in Materials. DIMAT 2000. Switzerland: Ed. Y. Limoge and J.L. Bocquet, Scitec Publications, 2001, pp. 1631-1636.

[11] SHATYNSKI, S.R., HIRTH, J.P., RAPP, R.A. A theory of multiphase binary diffusion. Acta Metallurgica. 1976, vol. 24, pp. 1071-1078.

[12] DRÁPALA, J., JOPEK, P., PETLÁK, D., HARCUBA, P., KUBÍČEK, P. Reactive diffusion upon planar dissolving of copper in solder melts. In: Grain Boundary Diffusion, Stresses and Segregation. Switzerland: Ed. By B.S. Bockstein, A.O. Rodin and B.B. Straumal. Special journal issue of Defect and Diffusion Forum, Trans Tech Publications, 2011, vol. 309-310, pp. 127-134. ISBN 978-3-03785-055-8, ISSN 1012-0386.

[13] DRÁPALA, J., STRUHAŘOVÁ, A., PETLÁK, D., VODÁREK, V., KUBÍČEK, P. Reactive diffusion at the cylindrical dissolving of copper in the solder melt. Special journal issue of Defect and Diffusion Forum. Switzerland: Trans Tech Publications, 2011, vol. 312-315, pp. 387-392. ISBN 978-3-03785-117-3, ISSN 1012-0386.

[14] KUBÍČEK, P., DRÁPALA, J. Study of reactive diffusion in the presence of dissolution of copper in the solder melt. Defect and Diffusion Forum. Switzerland: Trans Tech Publications, 2010, vol. 297-301, pp. 8-14.

[15] DRÁPALA, J., KUBíČEK, P., HARCUBA, P., VODÁREK, V., JOPEK, P., PETLÁK, D., KOSTIUKOVÁ, G., KONEČNÁ, K. Reactive diffusion at the contact of a solid phase with the solder melt. Defect and Diffusion Forum, 2012, vol. 322, pp. 41-72.

[16] DRAPALA, J., KUBICEK, P., VODAREK, V., HARCUBA, P. Reactive diffusion at the contact of a solid phase with the melt of solders. In: COST MP0602 Action - Handbook of High-Temperature Lead-Free soldering systems; vol. 3 Group Project Reports. Brno: ed. A. Kroupa, COST office, 2012, pp. 136-143, ISBN 978-80-905363-3-3.

[17] DRÁPALA, J. et al. Lead-free solders. Theoretical and experimental study of phase equilibria and properties of new types of solders. Monograph. Ostrava: Ed. ES of the VŠB - TU Ostrava, 2011, p. 218. ISBN 978-80-2482495-6. in Czech.

[18] ADDA, Y., PHILIBERT, J. Diffusion dans les métaux. PresseUniversitaire, Paris, 1966.

[19] GERCRIKEN, S.D., DECHTJAR, I.J. Diffusion in metals and alloys in solid state. (Difuzija $v$ metallachisplavach $v$ tvěrdoj faze). Moscow: Gos. izd. fiz.-mat. lit., 1960. in Russian.

[20] BALOGH, Z., SCHMITZ, G. Diffusion in metals and alloys. [online]. Chapter 5. Physical Metallurgy (Fifth Edition). 2014, pp. 387-559. Available from: https://doi.org/10.1016/B978-0-444-53770-6.00005-8. 